\title{
Tecnologia de informação e comunicação na escola pública: reflexões e desafios dos educadores
}

\author{
Anne Alilma Silva Souza Ferrete ${ }^{1}$, Rodrigo Bozi Ferrete ${ }^{2}$, Rogéria Dias Teixeira ${ }^{3}$ \\ ${ }^{1}$ Departameto de Educação -Programa de Pós-Graduação em Educação (PPGED) - \\ Universidade Federal de Sergipe (UFS) - São Cristóvão - SE - Brazil \\ ${ }^{2}$ Instituto Federal de Educação, Ciências e Tecnologia de Sergipe (IFS) - Aracaju - SE \\ - Brazil \\ ${ }^{3}$ Secretaria de Estado da Educação (SEED) - Aracaju -SE - Brazil \\ alilma.ferrete50@gmail.com, rbferrete@gmail.com, \\ rogeriadtex@yahoo.com.br
}

\begin{abstract}
This study aimed to analyze and understand the teacher's reflections and the influence of the laptop in the classroom during the implementation of the Project One Laptop per Child (UCA). The object of study focused on the statements of teachers with respect to use of laptop embedded in the elementary education, the College EMEF Pedro Izidio de Oliveira. With this research we hope to contribute for the removal of information about the options for expanding the conditions for using the laptop as a practice to be adopted increasingly by teachers in public education institutions in order that teachers are responsible to train thoughtful being, reflective and critical. The results allow us to conclude that teachers must become aware of their training and pedagogical practice, and that their efforts are extremely important for student development, as well, the need of them to be prepared for the use of technologies.
\end{abstract}

Resumo. $O$ presente estudo teve com o objetivo analisar e compreender as reflexões dos professores e a influência do computador portátil em sala de aula no decorrer da implementação do Projeto um computador por aluno (UCA). O objeto de estudo centrou-se nos depoimentos dos professores com relação ao uso do computador portátil incorporado ao ensino básico fundamental da escola EMEF Pedro Izídio de Oliveira. Com essa pesquisa espera-se contribuir para o levantamento das informações sobre possibilidades de ampliação das condições para o uso do laptop como prática a ser adotada cada vez mais pelos professores das instituições de ensino público, tendo em vista que os professores são encarregados de formar sujeitos pensantes, reflexivos e críticos. Os resultados obtidos permitem-nos concluir que os professores devem se conscientizar sobre sua formação e prática pedagógica, e que seus esforços são de extrema importância para o desenvolvimento do aluno, bem como das necessidades deles se prepararem para o uso das tecnologias. 


\section{Introdução/ Justificativa}

$\mathrm{O}$ momento requer profunda revisão do sistema educativo. Os educadores têm como tarefa, a formação das novas gerações, e, ao mesmo tempo criar estruturas de capacitação e qualificação profissional, respeitando a sua natureza e tendo consciência de que suas necessidades estão mudando, e a escola precisa acompanhar a evolução.

Como bem enfatiza Almeida (1999), a inserção da tecnologia na escola, e mais especificamente, o uso do computador portátil demanda certa mudança, quer no espaço físico da escola, quer na postura e atuação do professor no processo de ensino e aprendizagem.

No que concerne à estrutura física da escola, essa alteração não mais se refere à criação de laboratório de informática, mas à inserção e uso de tecnologias móveis em sala de aula. Segundo Mendes (2008), provoca transformações nas relações entre os elementos ocupantes daquele espaço e seus modos de atuação, estimulando, dessa forma, transformações no contexto escolar.

A atuação do professor no processo de ensino e aprendizagem requer dele uma formação continuada com foco nas práticas pedagógicas envolvendo o uso do computador, bem como uma reflexão sobre essas práticas na busca de detectar as dificuldades encontradas, e buscar soluções para que elas possam ser dirimidas.

Neste sentido, a preocupação é com a necessidade do professor se familiarizar com as tecnologias de informação e comunicação, o que poderá contribuir para diminuir o "analfabetismo tecnológico" e viabilizar a utilização das tecnologias móveis na escola. Além da apropriação tecnológica necessária ao docente, o uso da tecnologia de informação e comunicação em sala de aula poderá proporcionar a redução dos analfabetos tecnológicos, bem como do distanciamento proporcionado pela falta de domínio e uso destas tecnologias, especialmente pelos alunos da rede pública. Desta forma, o uso do computador nas escolas públicas, através do Projeto Um Computador por Aluno (UCA), permite que essas crianças e adolescentes usufruam e não fiquem segregadas do acesso a tecnologia. Assim, a realidade atual que vivenciam as escolas com a presença do projeto UCA, integrada ao uso das tecnologias, poderá se transformar tanto por causa da presença dos laptops no ambiente educacional como também pela forma como os professores poderão utilizá-los potencialmente como apoio pedagógico. É válido destacar que incluir digitalmente um indivíduo vai além de oferecer um ensino mediado pelo computador.

O professor ao utilizar a tecnologia móvel poderá proporcionar um ambiente educacional, e suscitar no aluno a problematização, a observação, o estímulo a uma visão crítica, viabilizar e ampliar a possibilidade de construção do conhecimento. Daí, ser necessário que o professor domine os recursos disponíveis no computador para que possa estimular o aluno a buscar o conhecimento, desafiá-lo a (re)construir esse conhecimento e promover, desse modo, o pleno desenvolvimento da criatividade e autonomia desse ator social. Não precisa ter receio de que seu aluno saiba mais que ele. É evidente que esse aluno tem maior facilidade de manusear as tecnologias, visto que desde cedo está cercado por uma série de tecnologias. Então, é preciso que o professor saiba usar esse potencial tecnológico do aluno para apoiá-lo pedagogicamente em sala de aula. 
Com estes pressupostos, o potencial pedagógico da tecnologia móvel ganha dimensões diferentes. Sob esta visão, justificamos a introdução das TIC na Educação, com objetivos educacionais, tais como o incentivo à pesquisa, entre outros, que tanto os educadores gostariam de poder promover, estimulando maiores interesses aos alunos.

Como a Informática é algo relativamente novo e requer mudanças, acaba por provocar polêmicas em todos os setores, inclusive na área de Educação, onde ainda se questiona a sua utilização e a aplicação no contexto histórico-escolar, competindo para com isso, a necessidade de reflexão quanto a criação de outros hábitos, e adoção de novos paradigmas para utilização dessa ferramenta tecnológica, através de capacitação e preparação dos docentes.

Por outro lado, podemos evidenciar o pensamento de Oliveira (2007) quando acrescenta, que é fundamental a integração das tecnologias de informação e comunicação (TIC) em atividades de ensino, que professores e alunos desenvolvam trabalhos também não-disciplinares, entendendo o conhecimento de forma transversal, que sejam aproveitadas as imaginações dos alunos em suas produções e, por fim, que seja promotora de uma educação inclusiva.

De outra forma, a tecnologia móvel se mostra como elemento motor dos novos modos de produção, carecendo cada vez mais de indivíduos com formação profissional que lhe possibilite desenvolver conhecimentos teóricos, técnicos e operacionais voltados à produção de bens e serviços, além da exigência cada vez maior de formação em uso de tecnologias, que demonstrem qualidade e que sejam flexíveis, eficientes e eficazes no universo de campos de trabalho. Segundo Silva (apud CATTANI, 1997, p. 173) "[...] equipamentos informatizados de diferentes configurações têm sido introduzidos nos mais diferentes campos da atividade humana e não só na produção industrial".

A Informática tem tido grande importância devido a sua capacidade de transformação em todos os setores da vida, nas diversas áreas de trabalhos, como nas telecomunicações, na imprensa, na medicina, na segurança, no ensino etc., embora, existam grandes polêmicas quanto a possibilidade de "substituição" do homem pelo computador nos meios produtivos e de ensino e aprendizagem, devido ao grande contingente de excluídos desses processos.

Nesse sentido, poderíamos pensar na necessidade de promover inclusão digital desses alunos, com a incorporação das tecnologias móveis no ensino público. Podemos verificar que é muito pouca a familiarização do pessoal com o emprego do computador como instrumento educacional, enquanto constatamos a boa vontade dos alunos em se fazerem presentes, motivados com a utilização do computador portátil em sala de aula, como fonte de pesquisas na Internet ou até mesmo, para produzirem trabalhos com utilização dos diversos softwares, de acordo com as exigências de suas respectivas áreas. As inovações tecnológicas, das últimas décadas para cá, não só modificaram a maneira de produzir como também de organizar o mundo do trabalho, acelerando, assim, a absorção diversificada do trabalho qualificado nos diversos setores da economia.

Considerando que os processos de aprendizagem possam inserir indivíduos que compõem as novas gerações, no mundo da cultura e da sociedade, quando estes processos acenam para uma educação crítico-emancipatória, com uma linguagem voltada 
ao entendimento, capaz de garantir a esses indivíduos a formação de suas personalidades. Esse pensamento comunga com a assertiva de Boufleuer (1997, p. 69), que diz:

\begin{abstract}
A educação, para obter um bom êxito no cumprimento de suas metas gerais de transmitir tradições culturais, de renovar solidariedades e de socializar as novas gerações, necessita ser concebida por seus agentes como uma ação comunicativa. A recorrência a uma linguagem voltada ao entendimento é, por assim dizer, a condição a priori, de possibilidade da própria experiência educativa.
\end{abstract}

Diante dessas considerações, faz-se necessário repensar sobre a abordagem dos conteúdos de ensino, bem como a sua prática. Isso poderá possibilitar que os indivíduos realizem seus planos, suas pesquisas em comum acordo, ou seja, entre professores, seus pares e a equipe de formação, de acordo com uma situação pré-definida e presente nas relações entre os indivíduos. Para tanto, segundo Oliveira (2004) é importante aproveitar a volatilidade, a interatividade e a flexibilidade das tecnologias digitais, potencializando práticas multiculturais, inclusivas, pensando no currículo escolar e integrando as ações previstas no Projeto Um Computador por Aluno.

\title{
2. Procedimentos metodológicos
}

Acreditamos que definir o método seja primordial para o bom desenvolvimento de uma pesquisa, que tem seu êxito medido pela escolha e aplicação dos modelos mais adequados e que permitam o alcance pleno dos seus objetivos.

Desta forma, a natureza da pesquisa teve um caráter exploratório, de modo que permitiu uma visão mais precisa das reflexões dos educadores, tendo em vista as mudanças na cultura escolar, ocorridas diante da utilização da tecnologia móvel no cotidiano da Escola Municipal de Ensino Fundamental Pedro Izídio de Oliveira, situada no povoado Montes Coelho, Tobias Barreto - SE. Fez-se necessário, portanto, delimitar primeiramente o nível de utilização do computador portátil dentro da Instituição, pois com a chegada das TIC nas escolas da rede pública, surgiu a necessidade de novos desafios com relação à formação de professores e gestores, para que o uso do laptop se efetivasse como apoio nas atividades pedagógicas, ou seja, a tecnologia realmente integrasse o currículo escolar, com objetivo de promover a cultura digital na instituição.

Diante do que foi descrito anteriormente, sentimos necessidade de esboçar uma análise dos depoimentos dos professores e gestores, sobre a inserção da tecnologia no cotidiano da escola. A metodologia de análise dos dados se dá por meio da coleta das respostas postadas no ambiente colaborativo de aprendizagem e-proinfo, (http://www.eproinfo.mec.gov.br), versão 2.0, do Ministério da Educação. Os discursos foram coletados do Fórum correspondente à atividade 3.1: Papel das Tecnologias integradas ao currículo; do módulo IV que trata da Elaboração de Projeto. Desta forma, apresenta-se o relato dos educadores participantes da pesquisa retratando suas experiências.

Realizamos também, observações do cotidiano, registradas em uma ficha de observações e posteriormente tabuladas. $\mathrm{O}$ acompanhamento dessas atividades desenvolvidas foi feito com a presença da professora da disciplina em sala de aula e com o uso do laptop.

Neste sentido, Chizzotti (s.d: 85) é da opinião que: 
Observando a vida cotidiana em seu contexto ecológico, ouvindo as narrativas, lembranças e biografias, e analisando documentos, obtémse um volume qualitativo de dados originais e relevantes, não filtrados por conceitos operacionais, nem por índices quantitativos.

Ressaltamos a importância da observação do cotidiano escolar para validação dos dados coletados. Na etapa final do acompanhamento, fizemos uma análise dos resultados das atividades produzidas pelos alunos, objetivando obtenção de breves comentários dos discentes e educadores. Concluindo, o que esperamos é que, com os instrumentos anteriormente mencionados, tenhamos coletado dados não isolados, pois foi através destes que tivemos a possibilidade de visualizar a essência do problema a ser investigado.

\section{Reflexões dos educadores}

No tocante à formação dos educadores da E. M. E. F. Pedro Izídio de Oliveira houve participação da gestora, da secretária, da coordenadora, bem como de professores regentes, nos módulos ofertados pelo curso. Desde o início essa participação demarcou uma capacitação de acordo com o pensamento de Almeida \& Prado (2009) que enfatizam uma formação que contemple os diferentes profissionais da gestão, em especial os gestores e coordenadores pedagógicos.

Nesse sentido, pode-se dizer que a formação na escola Pedro Izídio de Oliveira apresentou perspectivas de resultados significativos, pois seu corpo docente, bem como sua equipe diretiva, tiveram oportunidade de refletir sobre a prática pedagógica e reconstruí-la para torná-la mais efetiva. Isto pode ser confirmado com o relato da educadora participante do curso:

[...] Percebemos esse processo no trabalho com o projeto Drogas realizado na Escola Municipal Pedro Izidio de Oliveira. Todo o projeto foi montado para ser trabalhado com a utilização do computador em sala de aula e com os meios tecnológicos áudios visuais como data show. Foi possível perceber que houve aprendizagem, e um conhecimento significativo [...].

Observou-se com essa prática pedagógica, que a formação dos educadores, voltada para o uso da tecnologia na escola, apresentou um perfil construtivista. Este fato foi verificado no ambiente escolar, visto que os alunos foram estimulados a participar diretamente na construção do conhecimento, pois participaram de pesquisa na internet sobre o efeito das drogas. Fizeram cartazes sobre o que aprenderam, entrevistaram pessoas da comunidade que são viciadas, enfim, os alunos construíram algo que realmente fez sentido. Eles tiveram oportunidade de aprender fazendo. Houve um envolvimento afetivo e cognitivo que gerou uma aprendizagem significativa, comprovado pelos resultados das diversas experiências utilizadas.

Vale ressaltar ainda que a formação contempla justamente a questão da contextualização, que possibilita ao professor reconstruir a sua própria prática pedagógica através da integração do computador com o currículo. 
Diante dessa nova realidade uma questão fez-se presente: qual a posição dos educadores da E. M. E. F. Pedro Izídio sobre a inclusão digital no cotidiano da escola? Para responder essa questão, faz-se necessária a análise dos comentários disponibilizados no Fórum: Papel das tecnologias integradas ao currículo, do módulo IV - Elaboração de Projeto desenvolvido no ambiente virtual. A professora afirma:

[...] Experiências têm mostrado que as tecnologias podem trazer contribuições significativas ao desenvolvimento do currículo se houver clareza da intencionalidade pedagógica, isto é, se o uso das tecnologias ocorrer integrado a um projeto curricular que se proponha a desenvolver a capacidade de pensar e aprender com tecnologias. Complicado? Não, se compreendermos que também nós, educadores, estamos aqui aprendendo por meio da integração de tecnologias, ao currículo deste curso. O principal objetivo, defendido hoje, ao adaptar a Informática ao currículo escolar, está na utilização do computador como instrumento de apoio às matérias e aos conteúdos lecionados, além da função de preparar os alunos para uma sociedade informatizada. Vivemos em um mundo tecnológico, onde a Informática é uma das peças principais.

No relato acima, a participante mostra que tem experiências com a tecnologia inserida na escola e conhecimento de seus resultados positivos. Mas, chama à atenção para a intencionalidade pedagógica dessa inserção, isto é, que não se deve inserir a tecnologia pura e simplesmente sem uma clareza do objetivo. Ela enfatiza que o uso da tecnologia precisa estar atrelado a uma proposta curricular que desenvolva a parte cognitiva do aluno. Embasa sua posição, dando o próprio exemplo de aprendizado por meio da tecnologia, durante o curso que está realizando. Além disso, afirma que a função do computador é de dar apoio às disciplinas ensinadas.

O trecho abaixo traz o depoimento de outra professora regente:

[...] A tecnologia pode contribuir de forma significativa no desenvolvimento do currículo quando há clareza da intencionalidade pedagógica, ou seja, se o uso das tecnologias ocorrer integrado a um projeto curricular que se proponha à capacidade de pensar e de aprender com tecnologias. As tecnologias vão auxiliar na compreensão das problemáticas atuais e na busca de alternativas para a transformação do cotidiano e a construção da cidadania. Buscar e organizar informações, utilizando tecnologias e diversas mídias, contribui para a valorização de novas formas de representação do conhecimento, utilizando diferentes linguagens que mobilizam o pensamento criativo, também sentimentos e representações, contribuindo para a comunicação e a interação entre pessoas e objetos de conhecimento, a aprendizagem e o desenvolvimento de produções colaborativas dentro da escola.

Vê-se neste discurso que a participante também compreende o uso da tecnologia em consonância com um currículo que tenha clareza na proposta pedagógica e proponha o desenvolvimento do pensar e do agir, para solucionar problemas do cotidiano, além de 
buscar alternativas para a construção da cidadania. Outro aspecto importante ressaltado pela participante é de que a tecnologia promove a aprendizagem e o desenvolvimento de produções colaborativas na escola.

Diante dessas posições, percebe-se que as cursistas compartilham de opiniões convergentes. Deixam bem notório que a tecnologia deve ser utilizada de forma integrada ao currículo e haja clareza de objetivos nessa utilização.

Outro relato de um participante da equipe gestora da escola apresenta uma visão interessante e é esboçado a seguir:

[...] Não quero aqui, questionar a importância da tecnologia dentro ou fora da escola. Todos os recursos que são incrementados ao currículo são de grande valia desde que seja utilizado com responsabilidade. $\mathrm{O}$ uso do computador como instrumento de apoio às disciplinas e aos conteúdos lecionados é muito bom como também, a sua função de preparar os alunos para uma sociedade cada vez mais informatizada. $\mathrm{O}$ meu desejo mesmo, é despertar em um único aluno o prazer de ler um bom livro, pena que nenhuma tecnologia me fez alcançar este objetivo.

A declaração acima torna evidente a certeza que a participante compreende a relevância do uso de forma potencial da tecnologia integrada ao currículo escolar, mas chama à atenção para o seu uso com responsabilidade. Também esclarece a importância do computador como apoio às disciplinas e à preparação que ele pode proporcionar ao discente, introduzindo-o na sociedade vigente que se encontra hoje com a informática cada vez mais inserida no cotidiano.

Outro aspecto observado em um dos fóruns foi o discurso em tom de desabafo de um docente. Declara o desejo de despertar o prazer da leitura nem que seja em um aluno e relata que nenhuma tecnologia foi capaz de realizar esse sonho tão almejado. Mas, essa é uma realidade cada vez mais notória entre os educadores. Através de desabafos constantes os discentes tem colocado o mesmo aspecto, principalmente no ensino superior, no qual tem sido cada vez mais evidente, tendo em vista a dificuldade de leitura e a falta de embasamento teórico dos discentes de forma em geral.

Vê-se que, conforme evidenciado anteriormente, os participantes entendem o quanto é importante utilizar de forma potencial a tecnologia móvel na escola e o papel do professor diante de tal realidade. No último relato há uma espécie de frustração por parte da participante, uma vez que não obteve êxito em fazer leitores com a ajuda do computador portátil.

Outro ponto de vista de um professor sobre inserção tecnológica na escola:

[...] nos dias atuais em que a tecnologia cada vez mais faz parte do nosso cotidiano, é de fundamental importância sabermos um pouco sobre a mesma. O uso da tecnologia na escola só enriquece a aprendizagem dos alunos e facilita o trabalho do professor, pois torna as aulas muito mais dinâmicas e menos cansativas. Dessa forma prende-se mais a atenção dos alunos aos conteúdos de cada disciplina e 
assim, ganha o professor e principalmente os alunos, pois as trocas de informações passam a ocorrer mais intensamente.

Aqui se percebe que o docente tem plena convicção dos benefícios da tecnologia na escola. Ele elenca os pontos positivos dentre os quais se destacam a dinamicidade das aulas e o dialogismo entre docente e discente na troca de informações. Vale lembrar que fica evidenciado a mudança na relação professor-aluno e na comunicação entre os mesmos, tendo como consequência, a amplitude de acesso as informações e a possibilidade de promover a construção do conhecimento dos alunos, que acontece de forma mais acentuada.

\section{Considerações finais}

De modo geral, os relatos dos participantes dos fóruns demonstram que a Instituição em estudo, conta com a possibilidade de resultados satisfatórios pelo uso da tecnologia móvel como ferramenta de apoio pedagógico.

Valorizamos na Escola EMEF Pedro Izídio de Oliveira, a utilização de uma metodologia apoiada nos saberes adquiridos pelos docentes e discentes, integrando suas experiências e desenvolvendo suas capacidades reflexivas, integrando a escola e as diversas disciplinas.

Em nossa pesquisa, registramos, então, que a visão dos professores, segundo depoimentos, com relação ao uso da tecnologia computacional em sala de aula, não se reveste de características especiais, porém, considera como um potencial pedagógico a ser assimilado e aproveitado para melhoria do ensino. Assim, percebemos que as professoras que participaram efetivamente da pesquisa, reconhecem a importância e a necessidade de profundas reflexões sobre a realidade e suas práticas, em relação ao que os demais educadores da escola vivenciam atualmente.

A participação dos professores nos fóruns foi de vital importância para que pudéssemos ter uma visão ampla do ponto de vista desses educadores, seus anseios, preocupações, consciência e dificuldades encontradas em relação à utilização desse recurso tecnológico. Totalmente a favor de uma inserção tecnológica integrada ao currículo com objetivos claramente delineados. Isso aliado a um senso de responsabilidade em manusear a informação que será adquirida com o uso da tecnologia.

De acordo com as experiências, vivenciada pelos educadores, estes poderão continuar assumindo uma postura diferenciada e refletindo suas práticas. Como bem enfatiza Ferrete (2007, p. 34),

Para isso, o docente precisa compreender o que ele faz, o que precisa fazer para atingir os objetivos a que se propõe, bem como relacionar e integrar diferentes conteúdos, procurando refletir sua própria prática. Seu acompanhamento, poderá ser feito de forma constante, até que o professor se sinta seguro diante das diferentes aplicações da tecnologia no seu cotidiano, oferecendo condições e auxiliando-o na resolução de seus problemas, mantendo uma reflexão interdisciplinar constantemente 
renovada diante das transformações da sociedade e, contribuindo para construção de novos conhecimentos.

Corroborando com o exposto, diante dessa necessidade constante de reflexão e do envolvimento maior entre os docentes, as falas dos educadores denunciam a necessidade de eles assumirem, de uma vez por todas, essa realidade: a presença da tecnologia de informação e comunicação nas atividades do cotidiano e nas relações sociais. Este fator contribui para que compreendam melhor os desafios e mudanças que suas ações sofrerão ao longo de sua jornada educacional. Jornada esta que exigirá o desenvolvimento de estratégias pedagógicas para o uso do computador em sala de aula.

Diante do que foi exposto, há necessidade de que a escola tome como prática, o estabelecimento de espaços para reflexão e avaliação sobre a educação e tecnologia, visando uma melhoria continuada dos seus processos educativos, o que poderá contribuir muito para sua promoção.

Desta forma, podemos sugerir, primeiramente, que a escola proporcione mais cursos de capacitação de forma contínua para os professores, e contribuam para utilização dos recursos tecnológicos com o uso de softwares educativos, demonstrando a utilidade do computador como uma ferramenta que servirá como apoio pedagógico. Conforme descrito anteriormente, esta tecnologia inserida no processo de ensino/aprendizagem, bem como a possibilidade de se montar grupos de estudos para a troca de experiências, assessoramento e suporte em relação à incorporação e utilização das tecnologias educacionais, conforme preocupação evidenciada nessa pesquisa.

\section{References}

Almeida. Maria Elizabeth B. de. (1999) "Ensinar e aprender com o computador: Articulação inter-trans-disciplinar”, Boletim Salto para o Futuro, Brasília. Informática na educação.

Almeida, Maria E. B. de and PRADO, Maria E. B. B. (2009) Formação de educadores para o uso dos computadores portáteis: indicadores de mudança na prática e no currículo. In: Conferência Internacional de Tecnologias de Informação e Comunicação na Educação, 6, Braga, 2009. “Anais ...” Braga, Portugal: Universidade do Minho.

Belloni, M. L. (2001) "O que é mídia-educação", Campinas, SP, Autores Associados, (Coleção polêmicas do nosso tempo; 78).

Boufleuer, José P. (1997) "Pedagogia da ação comunicativa: uma leitura de Habermas". Ijuí, Ed. UNIJUÍ. (Coleção Educação).

Carvalho, Ruy de Q. (1994) "Capacitação tecnológica, revalorização do trabalho e Educação", In: FERRETI, João Celso et al. Novas Tecnologias, Trabalho e Educação, Petrópolis: Vozes.

CATTANI, A. D. et al. (1997) “Trabalho e Tecnologia, Dicionário Crítico”, Petrópolis: Vozes. 
Chizzotti, A. "Pesquisas em Ciências Humanas e Sociais", São Paulo: Cortez, s.d.

Demo, P. (1994) "Pesquisa e construção de conhecimento: Metodologia científica no caminho de Habermas", Rio de Janeiro, Tempo Brasileiro.

- (2000) "Educação e conhecimento: Relação necessária, insuficiente e controversa", Petrópolis, RJ, Vozes.

Ferrete, Anne A. S. S. (2007) Sala de aula virtual: análise de um espaço vivido na EAD. In: França, Lilian C. M.; Ferrete; Anne A. S. S.; Gouy, Guilherme B. (Orgs.). "Tecnologias da Informação e da Comunicação aplicadas à Educação". São Cristóvão, Universidade Federal de Sergipe, CESAD/UFS.

Mendes, M. (2008) "Introdução do Laptop Educacional em sala de aula: Indícios de mudanças na organização e gestão de aula”, Dissertação (Mestrado em Educação) PUCSP, São Paulo.

Oliveira, J. M. A. (2004) "O hipertexto como imaginação do currículo e de conhecimentos produzidos na escola”, Ano 2 - Voll.

Petitto, S.A. (2003) "Projetos de trabalho em informática: Desenvolvendo competências", Campinas, SP, Papirus. (Coleção Papirus Educação).

Silva, B. D. (1998) "Educação e comunicação", Tese (Doutorado em Educação) Universidade do Minho, Braga, pages 278-284.

Silva, Â. M. C; et al. (2003) O Centro de Educação Federal do Rio Grande do Norte e as novas tecnologias de educação. In: TORRES, P. L. (Org.), "Pionerismo em educação à distância: a experiência do Rio Grande do Norte”, Natal, CEFET/RN, pages 111-133.

Valente, J. A.; MAZZONE, J. S.and BARANAUSKAS, M. C. C. A. (2007) "Aprendizagem na Era das Tecnologias Digitais: Conhecimento, trabalho na empresa e design de sistemas", São Paulo, Cortez Editora, v. 1. 271 p.

Valente, J. A.(Org.). (2003) "Formação de educadores para o uso da informática na escola". Campinas, SP, UNICAMP/NIED. 